Article

\title{
Exploration of a Chemo-Mechanical Technique for the Isolation of Nanofibrillated Cellulosic Fiber from Oil Palm Empty Fruit Bunch as a Reinforcing Agent in Composites Materials
}

\section{Ireana Yusra A. Fatah ${ }^{1}$, H. P. S. Abdul Khalil ${ }^{1, *}$, Md. Sohrab Hossain ${ }^{1}$, Astimar A. Aziz ${ }^{2}$,} Yalda Davoudpour ${ }^{1}$, Rudi Dungani ${ }^{3}$ and Amir Bhat ${ }^{4}$

1 School of Industrial Technology, Universiti Sains Malaysia, 11800 Penang, Malaysia; E-Mails: ireanayusra@gmail.com (I.Y.A.F.); sohrab_hossain2005@yahoo.com (M.S.H.); y.davoudpour@gmail.com (Y.D.)

2 Malaysian Palm Oil Board (MPOB), Agro Product Unit, Engineering and Processing Division, Jalan Sekolah Pekan Bangi Lama, 43000 Kajang, Malaysia; E-Mail: astimar1@gmail.com

3 School of Life Sciences and Technology, Institut Teknologi Bandung, Jalan Ganesha No. 10, Bandung 40132, Indonesia; E-Mail: r.dungani@gmail.com

4 Department of Fundamental and Applied Sciences, Universiti Teknologi Petronas, 31750 Tronoh, Perak, Malaysia; E-Mail: ahbhat@yahoo.com

* Author to whom correspondence should be addressed; E-Mail: akhalilhps@gmail.com; Tel.: +60-4653-2200; Fax: +60-4657-3678.

External Editor: Alexander Böker

Received: 25 July 2014; in revised form: 22 September 2014 / Accepted: 30 September 2014 / Published: 21 October 2014

Abstract: The aim of the present study was to determine the influence of sulphuric acid hydrolysis and high-pressure homogenization as an effective chemo-mechanical process for the isolation of quality nanofibrillated cellulose (NFC). The cellulosic fiber was isolated from oil palm empty fruit bunch (OPEFB) using acid hydrolysis methods and, subsequently, homogenized using a high-pressure homogenizer to produce NFC. The structural analysis and the crystallinity of the raw fiber and extracted cellulose were carried out by Fourier transform infrared spectroscopy (FT-IR) and X-ray diffraction (XRD). The morphology and thermal stability were investigated by scanning electron microscopy (SEM), transmission electron microscopy (TEM) and thermogravimetric (TGA) analyses, respectively. The FTIR results showed that lignin and hemicellulose were removed effectively from the extracted cellulose nanofibrils. XRD analysis revealed that the percentage of crystallinity was 
increased from raw EFB to microfibrillated cellulose (MFC), but the decrease for NFC might due to a break down the hydrogen bond. The size of the NFC was determined within the 5 to $10 \mathrm{~nm}$. The TGA analysis showed that the isolated NFC had high thermal stability. The finding of present study reveals that combination of sulphuric acid hydrolysis and high-pressure homogenization could be an effective chemo-mechanical process to isolate cellulose nanofibers from cellulosic plant fiber for reinforced composite materials.

Keywords: nanofibrillated cellulose; oil palm empty fruit bunch; high pressure homogenization; acid hydrolysis; composite materials

\section{Introduction}

Cellulose is considered an almost inexhaustible source of raw material in the increasing demand for environmentally friendly and biocompatible products [1,2]. The excellent mechanical properties, remarkable reinforcing capability, low density, thermal stability, and environmental benefits of cellulose have attracted scientists' interest in utilizing cellulosic fibers to develop environmentally friendly composite materials. Over the years, numerous studies have been conducted on the isolation nanofibres from various cellulosic sources, such as oil palm biomass [3-6], wood pulp [7], kenaf [8,9], bamboo [10], flax [11,12], and rice straw [13]. Palm oil nations are generating largest amount of oil palm biomass in the form of empty fruits bunches and fruits shell, arising serious environmental impacts [3]. It has been reported that Malaysia alone produces about 40 million tons of oil palm biomass annually including 280,000 tons empty fruit bunches, representing an abundant, inexpensive, and readily available source of lignocellulosic biomass [14,15]. Moreover, the cellulose content in oil palm empty fruit bunch (OPEFB) is $44.4 \%$ along with $30.9 \%$ hemicellulose and $14.2 \%$ lignin [3]. This very large generation of OPEFBs, and its high cellulose content, have attracted a great deal of research interest to produce nanocellulose for use as a reinforcing agent in composites materials.

The term microfibrillated cellulose (MFC) is applied to those fibril aggregates with a diameter between 30 and $100 \mathrm{~nm}$ and of several micrometers in length. However, MFC can also be considered as nanofibrillated cellulose (NFC), as the definition of NFC is a size $<100 \mathrm{~nm}$ in one dimension [8]. Nano-size cellulose, which can be considered as a nanofiber, has attracted a great deal of attention during the past few years. Nanocellulose extracted from plant, agricultural/forest crops or residues can be classified in two main subcategories, nanofibrillated cellulose (NFC) and nanocrystalline cellulose (NCC), based on the cellulosic source and the processing conditions. NCC exhibits straight crystalline rod-like shapes, and has relatively a lower aspect ratio with a typical diameter of 2-20 nm. The length varies between 100 and $500 \mathrm{~nm}[6,12]$. The particles are highly crystalline and vary between $54 \%$ and $88 \%$ [6]. NFC is a long, flexible, entangled network with a diameter of approximately 1-100 nm. They consist of alternating crystalline and amorphous domains [16].

There are various methods for preparing nanocellulosic fibers from cellulose fibers including chemical treatment, mechanical treatment, and chemo-mechanical treatment processes $[1,3-8,16,17]$. Acid hydrolysis has been extensively studied to isolate nanofibers from different cellulosic sources $[3,11,16]$. It is being reported that hydrolysis conditions, such as acid-to pulp ratio, reaction 
time, temperature, and acid type, have a remarkable influence on the dimensions and surface charge of the cellulose nanofibers. Sulphuric acid $\left(\mathrm{H}_{2} \mathrm{SO}_{4}\right)$ and hydrochloric acid $(\mathrm{HCl})$ are commonly used in the acid hydrolysis process for NCC production to remove the amorphous regions $[11,16]$. However, sulphuric acid provides a highly stable aqueous suspension with the introduction of sulphate groups on the surface of crystallites [8,11]. Fahma et al. [3] successfully extracted cellulose nanofibers from OPEFBs using sulphuric acid hydrolysis. The experimental results of the study reported that the percentage of crystallinity increased with increasing treatment time; while the degree of polymerization value decreased with treatment times over $60 \mathrm{~min}$. Though, acid hydrolysis offers potential advantages on the production of cellulose nanofibers, it has certain drawbacks in terms of productivity, composition and thermal properties. One of the major challenges of acid hydrolysis method on the isolation of cellulose nanofibers is to increase the yield (typically around $30 \%$ in weight basis), which potentially limits scale-up by the acid hydrolysis method [11].

In recent years, high-pressure homogenizers (HPH) have been extensively used to isolate cellulose nanofibers from various lignocellulosic sources $[3,8,11,16]$. The HPH has been viewed as an efficient method for refining the fiber through high pressure. The HPH is not sufficient to fibrillate cellulose into nano-sizes, requires pre-treatment and combination of further mechanical treatment to reduce the fiber size, and prevents from stacking the small orifice of HPH [14,18,19]. Jonoobi et al. [20] isolated kenaf nanofibers from bleached kenaf bast pulp by the combination of chemical and mechanical treatments. Chemical treatment was conducted as a pre-treatment of kenaf bast pulp using $\mathrm{NaOH}-\mathrm{AQ}$ (anthraquinone) and three stages of bleaching processes. In the mechanical treatment process, chemically-treated kenaf bast pulp was refining, cryo-crushing and subsequently homogenized using HPH. A study done by Jonoobi et al. [8] isolated cellulose nanofiber from OPEFBs using chemo-mechanical processes. Where in the mechanical step, bleached pulp was ground by a willey mill and then socked with distilled water prior to pass through HPH. However, grinding of cellulose pulp may prevent light scattering on the composite and the produced nanocellulose may reduce the thermal expansion properties [21].

Although acid hydrolysis and high pressure homogenization have been utilized to produce cellulose nanofiber, and viewed as effective with the combination of other cellulosic fiber processing methods, there are very few studies that have considered preparing cellulosic nanofiber from OPEFBs with the combination method of sulphuric acid hydrolysis and high pressure homogenization as a chemo-mechanical process. In a recent study, Pan et al. [22] effectively isolated cellulose nanowhisker from commercial microcrystalline cellulose using the combination of sulphuric acid hydrolysis and high-pressure homogenization. However, the study reported that the sulphuric acid concentration plays an effective role on the isolation of cellulose nanowhisker. Therefore, utilization of this sulphuric acid hydrolysis and high-pressure homogenization processes is bearing considerable interest regarding the production of nanofibrillated cellulose fiber from natural resources. Sulphuric acid hydrolysis can be conducted as a pre-treatment process of the cellulosic fiber, with the hypothesis that the utilization of low acid concentrations in the sulphuric acid hydrolysis process might fibrillate the micro-size cellulose (microfibrillate cellulose) fiber, since the acid to fiber ratio and treatment time plays an effective role on fibrillation and the properties of the cellulosic fiber. Subsequently, microfibrillate cellulose fiber (MFC) can be homogenized using HPH to produce nanofibrillated cellulose. 
Then, the present study was conducted to produce nanofibrillated cellulose (NFC) fiber from OPEFBs using sulphuric acid hydrolysis and high-pressure homogenization as a chemo-mechanical process. Where, low concentrate sulphuric acid was used to hydrolysis the cellulose fiber prior to pressure homogenization. Several analytical methods, including scanning electron microscopy, Fourier Transform Infrared spectroscopy, X-ray diffraction, and thermogravimetry analyses were employed to determine morphological and thermal properties of NFC fiber.

\section{Experimental Section}

\subsection{Materials}

Oil palm EFBs were obtained from Malaysian Palm Oil Board (MPOB, Kajang, Selangor, Malaysia). Analytical grade Sulpuric acid (95\%) and other chemicals, such as sodium hydroxide, sodium silicate, hydrogen peroxide, and magnesium sulphite, were supplied by Chembumi Sdn. Bhd., Penang, Malaysia.

\subsection{Preparation of Cellulose Fiber}

The oil palm empty fruits bunch (EFB) is a lignocellulosic biomass. The purification of the cellulosic fiber was performed by using soda pulping and subsequent acid bleaching processes in order to efficiently remove non-cellulosic materials from EFB. The EFBs were cut to $2-3 \mathrm{~cm}$ and dried in open air prior to exposing in soda pulping process. The pulping of EFB fibers was conducted following the optimized experimental conditions as determined by Wan Rosli et al. [23]. The optimized pulping conditions were: $\mathrm{NaOH}$ concentration $26.1 \%$; temperature $161{ }^{\circ} \mathrm{C}$ and time $100 \mathrm{~min}$. Approximately $200 \mathrm{~g}$ of EFB fiber was taken in a digester at ratio of cooking liquor to EFB fibers 10:1 and treated at $161{ }^{\circ} \mathrm{C}$ for $100 \mathrm{~min}$, wherein the heating time was found to be $60 \mathrm{~min}$ (the time duration required to reach to target temperature) and the exposure time was $40 \mathrm{~min}$. Subsequently, the pulps were washed in distilled water and then mechanically disintegrated in a three-bladed mixer for $1 \mathrm{~min}$ at a $2.0 \%$ of pulp consistency and screened on a $0.15 \mathrm{~mm}$ slits flat-plate screen.

The alkali hydrogen peroxide bleaching process was carried out in order to remove residual lignin from the EFBs soda pulps. The bleaching process was conducted using 5\% pulp consistency with 3\% $\mathrm{H}_{2} \mathrm{O}_{2}$ at $50{ }^{\circ} \mathrm{C}$ for $90 \mathrm{~min}$, where $0.5 \% \mathrm{MgSO}_{4}$ was used as alkali source. The $\mathrm{pH}$ of slurry was adjusted to 10 using $3 \% \mathrm{NaOH}$. After bleaching, the bleached slurry was washed to a neutral $\mathrm{pH}$ and then oven-dried at $60{ }^{\circ} \mathrm{C}$ for $24 \mathrm{~h}$.

\subsection{Preparation of Nanofibrillated Cellulose Fiber}

The bleached slurry ( $10 \mathrm{~g}$ ) was hydrolyzed in $30 \% \mathrm{H}_{2} \mathrm{SO}_{4}$ solution at $60{ }^{\circ} \mathrm{C}$ and acid to fiber ratio of 17.5:1 for $2 \mathrm{~h}$. The hydrolization process was terminated with adding cold distilled water. The diluted suspension was then centrifuged at $11,000 \mathrm{rpm}$ for $10 \mathrm{~min}$ and the precipitation was collected. The participation was re-suspended in distilled water under strong agitation, followed by the centrifugation. The process was repeated until the $\mathrm{pH}$ reached to constant value. Subsequently, the suspension was passed through a high-pressure homogenizer (HPH) (Model: HPH 2000/4, IKA company, Königswinter, Germany) 30 times at a pressure of $50 \mathrm{MPa}$. 


\subsection{Characterization}

\subsubsection{Morphology Analysis}

The morphology of raw, pulp, bleached and MFC fibers were determined by scanning electron microscopy (ZEISS EVO ${ }^{\circledR}$ MA10, Königswinter, Germany) at an acceleration voltage of $1.5 \mathrm{kV}$. The fiber surfaces were mounted on aluminum stubs and sputter coated with a thin layer of palladium to avoid electrostatic charging during examination. Further, NFC fibers were studied using a Transmission Electron Microscope (TEM, Philips CM12 instrument, Amsterdam, The Netherlands). A drop of suspension was placed on a carbon-coated grid and allowed to dry at room temperature for $24 \mathrm{~h}$. The mean size distribution was recorded using an Image Analyzer.

\subsubsection{Fourier Transform Infrared Spectroscopy}

The changing of the functional groups of samples at each step was determined by Fourier transform infrared spectroscopy (FT-IR) using the $\mathrm{KBr}$ method. About $0.5-1.0 \mathrm{mg}$ samples in powder form were mixed with potassium bromide using a mortar. Then, the mixture was pressed to form a disk. The spectroscopy was recorded using a FT-IR Nicolet iS10 spectrometer (Thermo Fisher Scientific Inc., Waltham, MA, USA) in the frequency range of $4000-500 \mathrm{~cm}^{-1}$.

\subsubsection{X-ray Diffraction Analysis}

X-ray diffraction (XRD) patterns of sample were obtained using a Philips PW1050 X-pert diffractometer. $\mathrm{Cu} \mathrm{K \alpha}$ radiation: $5^{\circ}-70^{\circ}(2 \theta)$, scanning rate: $0.5{ }^{\circ} \mathrm{C} / \mathrm{min}$. The operation voltage and current were $40 \mathrm{kV}$ and $25 \mathrm{~mA}$, respectively. The crystallinity angle of the cellulose, $C_{\mathrm{IR}}$, was estimated according the method of Segal et al. [24]

$$
C_{\mathrm{IR}}(\%)=\frac{I_{200}-I_{\mathrm{AM}}}{I_{200}} \times 100
$$

where, $I_{200}$ signifies amorphous and crystalline fractions and $I_{\mathrm{AM}}$ shows the amorphous region.

\subsubsection{Thermogravimetric Analysis}

TGA of the samples was carried out using a Perkin Elmer Pyris series of TGA 6 (Waltham, MA, USA). About $3 \mathrm{mg}$ of the fibers were heated in nitrogen atmosphere with the heating rate of $20{ }^{\circ} \mathrm{C} / \mathrm{min}$. The temperature range was set between 30 and $900{ }^{\circ} \mathrm{C}$.

\section{Results and Discussion}

\subsection{Morphological Observation}

The changes of the fiber properties and the morphological structure of the treated fibers are important to predict the fiber-matrix interaction in the composite materials. SEM micrographs of the raw and treated fibers OPEFBs are presented in Figure 1. It was observed that the morphology of the fibers differs with the treatment process. Soda pulping and alkaline peroxide bleaching processes separated the fiber bundles into individual fibers with a significant decrease in fiber diameter. 
The surfaces of EFB raw fibers were uneven and tangled with lignin binder (Figure 1a). The raw EFB fiber is composed of bundles with continuous individual cells that are bound together by cemented components of lignin and hemicellulose. The surface seems irregular with these cementing and waxy materials. The diameters of the fibers were found to be around $50 \pm 2 \mu \mathrm{m}$. Soda pulping treated fibers had smooth and clear surfaces (Figure 1b). It was observed that the surface of the fibers look smoother than the raw fibers due to the removal of the impurities. This alkali treatment process helps in defibrillation and opening of the fiber bundles, thereby, the fiber diameter further reduced to $13 \pm 1 \mu \mathrm{m}$. As seen in Figure 1c, the bleached fibers using alkali hydrogen peroxide defibrillated the cellulose fiber with the diameter of $11 \pm 1 \mu \mathrm{m}$. This is attributed to the removal of lignin due to the bleaching process of soda pulping fibers and, thereby, decreased the fiber diameter. The bleaching treatment effectively modified the surface of the fibers, which appear smoother than the raw and unbleached pulp fibers.

The bleached slurry further treated with sulphuric acid hydrolysis by $30 \% \mathrm{H}_{2} \mathrm{SO}_{4}$ solution at $60{ }^{\circ} \mathrm{C}$, and an acid to fiber ratio of $17.5: 1$, for $2 \mathrm{~h}$ revealed that the size of the fibers slightly decreased to $9 \pm 1 \mu \mathrm{m}$, along with the shortened length of fibers (Figure 1d). It was observed that the morphological surface of treated fibers was not affected by the acid hydrolysis, but it exhibits in a smaller particle dimension with microfibrils formation. However, Fahma et al. [3] isolated nanofibrillated OPEFBs fiber $(100 \mathrm{~nm}-2 \mu \mathrm{m})$ using $64 \mathrm{wt} \% \mathrm{H}_{2} \mathrm{SO}_{4}$ solution at $45{ }^{\circ} \mathrm{C}$ and acid to fiber ratio of 10.5:1 for 15-90 min. Thus, formation and size of sulphuric acid hydrolysis treated fiber strongly depends on the acid concentration and acid to fiber ratio.

Figure 1. SEM (scanning electron microscopy) micrographs of oil palm EFB (empty fruit bunch) fibers: (a) raw fibers; (b) alkali treated fibers; (c) bleached fibers and (d) MFC (microfibrillated cellulose).

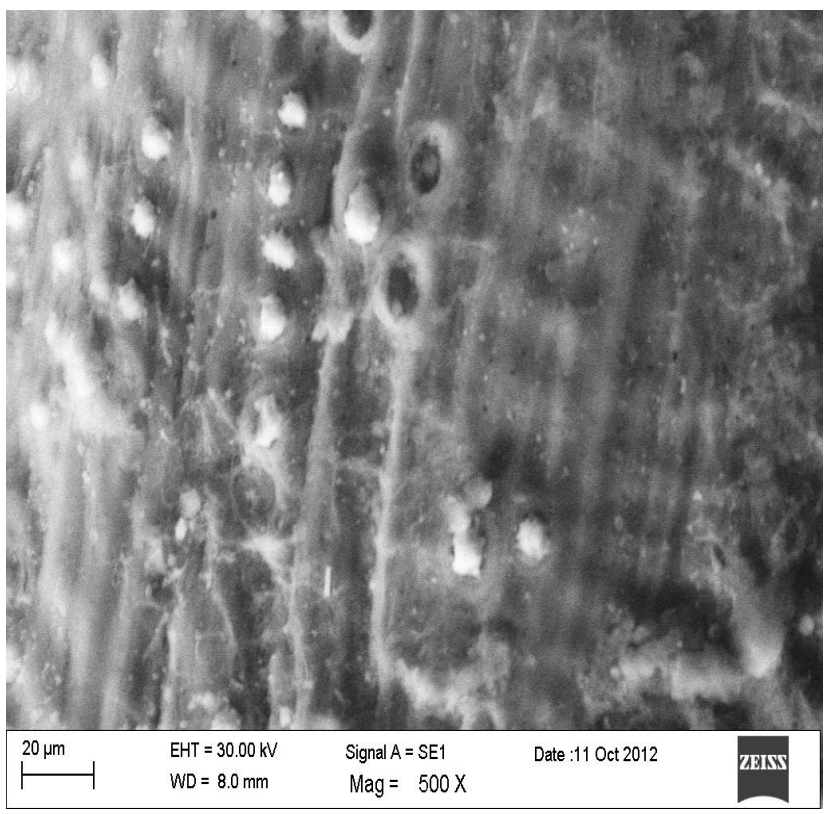

(a)

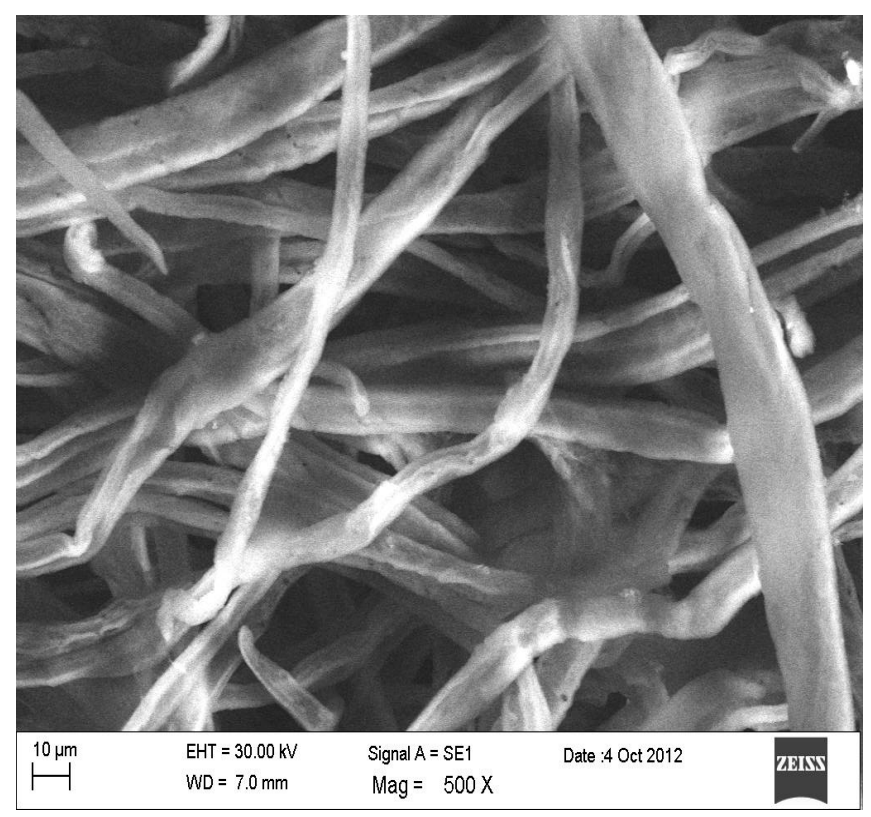

(b) 
Figure 1. Cont.

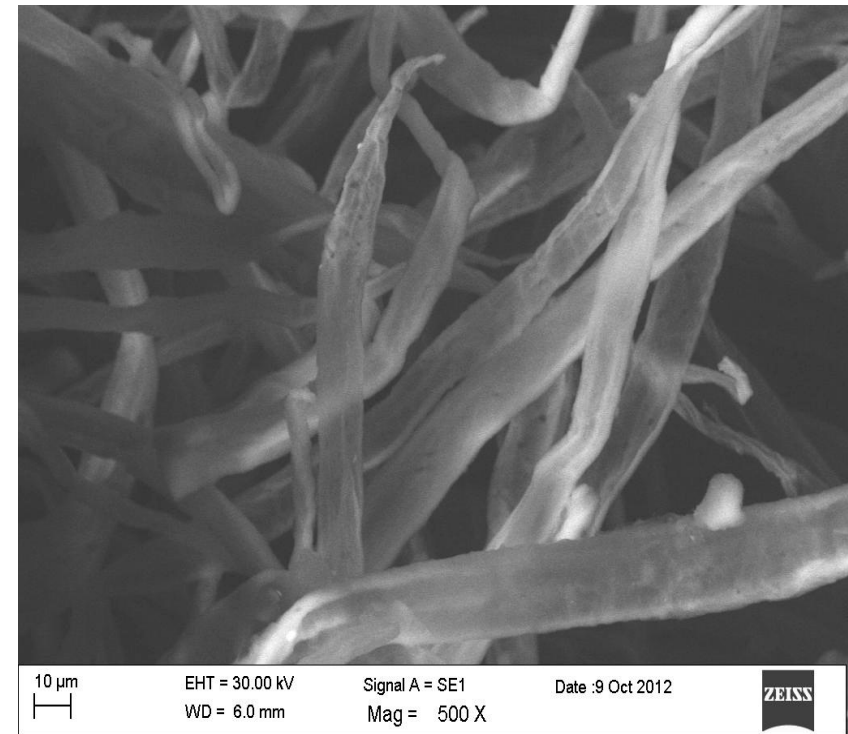

(c)

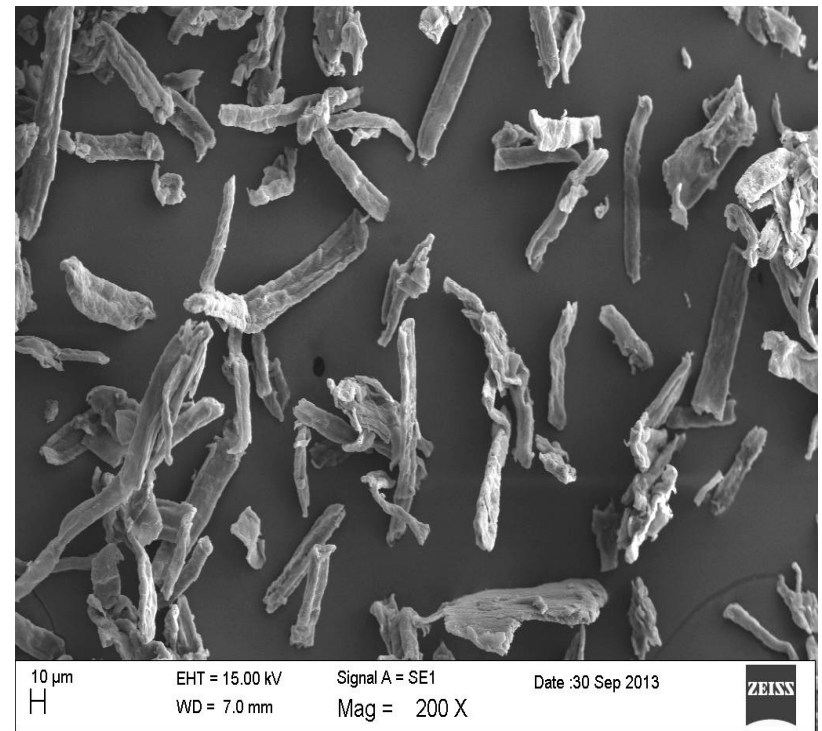

(d)

Transmission electron microscope (TEM) image analysis of NFC fibers produced using HPH treatment of MFC is shown in Figure 2. The TEM micrograph demonstrates the individual nanofibrils with little agglomeration. The nanofibrils range roughly around 5-10 $\mathrm{nm}$ in diameter. In the comparison with previous studies on the isolation of cellulose nanofiber using different chemo-mechanical processes, the diameter of 5-40 nm was gained for OPEFBs cellulose nanofiber [8] and 10-70 $\mathrm{nm}$ for kenaf nanofibers [20]. Thus, the combination of sulphuric acid hydrolysis and high-pressure homogenization processes is more effective on the isolation of cellulosic nanofibers.

Figure 2. TEM (transmission electron microscope) micrographs of NFC fibers at low and high magnifications: (a) 12,500×; (b) 50,000×.

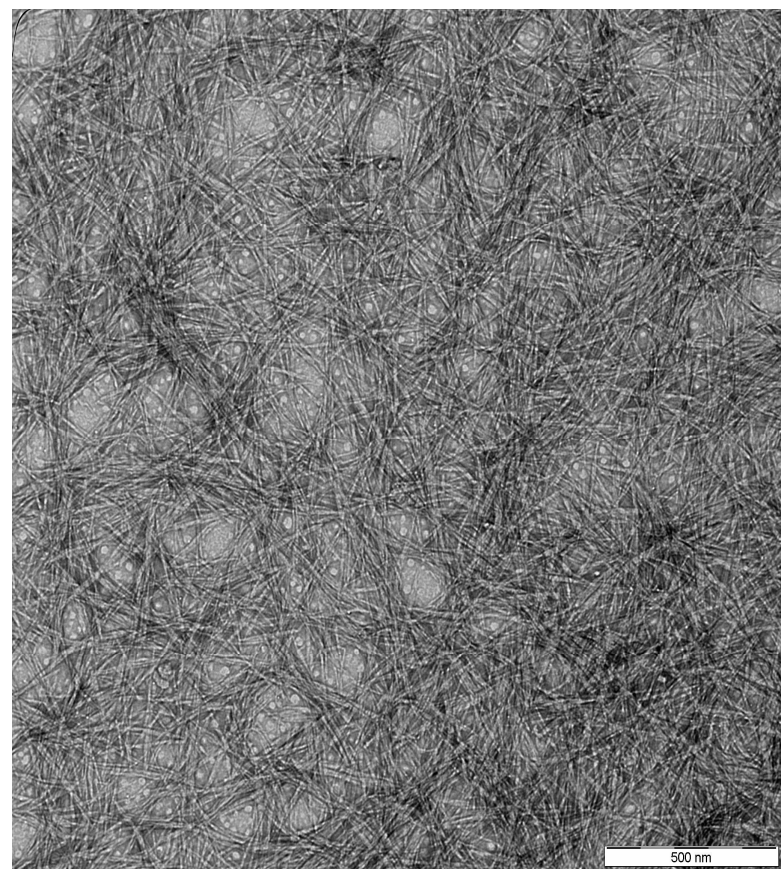

(a)

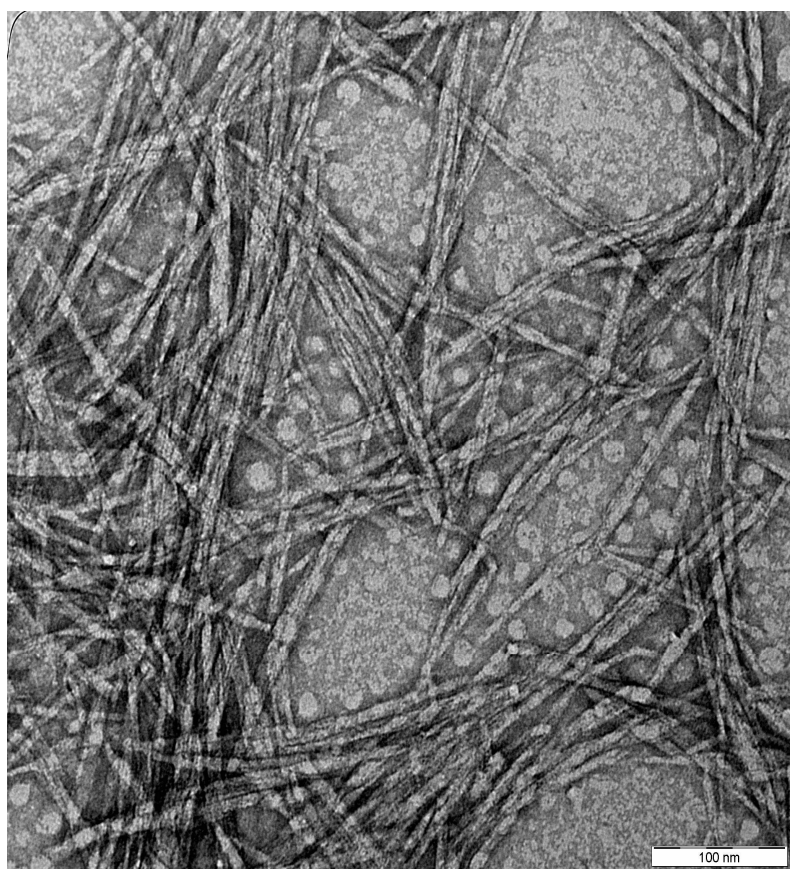

(b) 


\subsection{FT-IR Spectroscopy}

FT-IR spectra of the raw, pulp and bleached pulp of EFB fibers and that of MFC and NFC are shown in Figure 3. The FT-IR spectra obtained shows that the similar functional groups that appeared in most of the fibers studied indicated that the acid hydrolysis had not influenced the chemical structure of the treated fiber. The absorption bands at $3409 \mathrm{~cm}^{-1}$ represent the stretching vibration of $-\mathrm{O}-\mathrm{H}$ groups. The existence of the mixture of $\mathrm{O}-\mathrm{H}$ was due to the moisture content, where hydroxyl groups were found in cellulose, hemicelluloses, and lignin [25]. The asymmetric stretching vibration of $\mathrm{CH}_{2}$ was observed at $2907 \mathrm{~cm}^{-1}$ in the spectrum of all the types of fibers under study.

Figure 3. FT-IR (Fourier transform infrared spectroscopy) spectroscopy of oil palm EFB fibers: raw (R), pulp (P), bleached pulp (B), MFC and NFC.

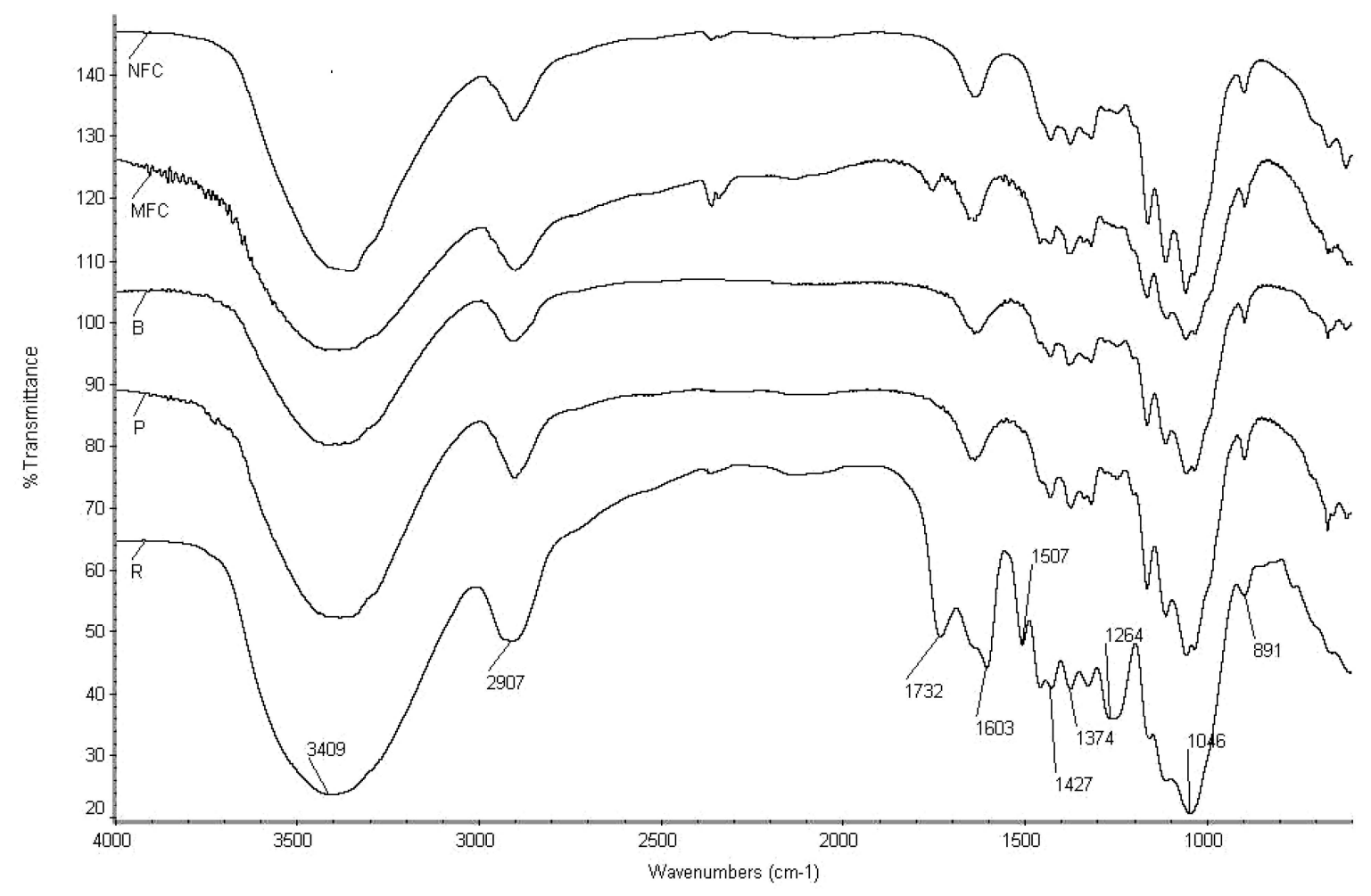

Comparing raw and NFC fibers, there is no detection of peak intensity at $1732 \mathrm{~cm}^{-1}$ for carbonyl $\mathrm{C}=\mathrm{O}$ stretching vibrations of the acetyl and uronic ester groups, suggesting the removal of pectin, hemicelluloses, or the ester linkage of the carboxylic group of ferulic and $p$-coumaric acids of lignin or hemicellulose in the raw fibers. The peak intensity at $1264 \mathrm{~cm}^{-1}$ present in raw fiber indicates the presence of the $\mathrm{C}-\mathrm{O}$ bond, out of plane stretching vibration of aryl group in the lignin. The absence of these two peaks in the spectra of the fibers other than raw fiber suggests more exposed $\mathrm{O}-\mathrm{H}$ groups and $\mathrm{CH}_{2}$, with the removal of lignin, hemicelluloses, and waxes. The peak at $1507 \mathrm{~cm}^{-1}$ is attributed to $\mathrm{C}=\mathrm{C}$ aromatic vibration in the lignin of the raw fiber [26], which disappears in the rest of the fibers. The absorption band at $1427 \mathrm{~cm}^{-1}$ is designed as a crystalline band and is attributed to the symmetric bending of $\mathrm{CH}_{2}[26]$.

Moreover, the vibration peaks at $1374 \mathrm{~cm}^{-1}$ in all the fiber samples indicate the presence of bending vibration of $\mathrm{C}-\mathrm{H}$ and $\mathrm{C}-\mathrm{O}$ bonds in the polysaccharide aromatic rings. The absorbance peak at 1603 to 
$1639 \mathrm{~cm}^{-1}$ in the spectra can be attributed to the $\mathrm{O}-\mathrm{H}$ bending vibration of the absorbed water. The peaks at $1046 \mathrm{~cm}^{-1}$ were characteristic of anhydroglucose chains with a $\mathrm{C}-\mathrm{O}$ stretch. The most significant peak intensity, which continually increases with alkali and bleaching treatment, and also in the subsequent size reduction treatments is $891 \mathrm{~cm}^{-1}$, which corresponds to the $\mathrm{C}-\mathrm{H}$ glycosidic deformation, with a ring vibration contribution and the $\mathrm{O}-\mathrm{H}$ bending. These features are characteristic of the $\beta$-glycosidic bond between the anhydroglucose units of the cellulose units that appears in all of the fibers. This band is also known as the amorphous band [27].

\subsection{X-ray Diffraction}

Figure 4 shows an XRD pattern of the raw and treated fibers along with MFC and NFC. All of the diffraction patterns showed peaks around $2 \theta=15^{\circ}$ and $22.7^{\circ}$ indicating the typical cellulose I structure. The only difference that is discernible is slight change in their peak intensities, representing some changes in the crystallinity of fibers. In fibers with high cellulose content, such as cotton and flax, generally two peaks at $16^{\circ}$ are observed but, in this case, only one broad peak at around $15^{\circ}$ confirms the presence of the amorphous material [11].

Figure 4. XRD of oil palm EFB fibers: raw (R), pulp (P), bleached pulp (B), MFC and NFC.

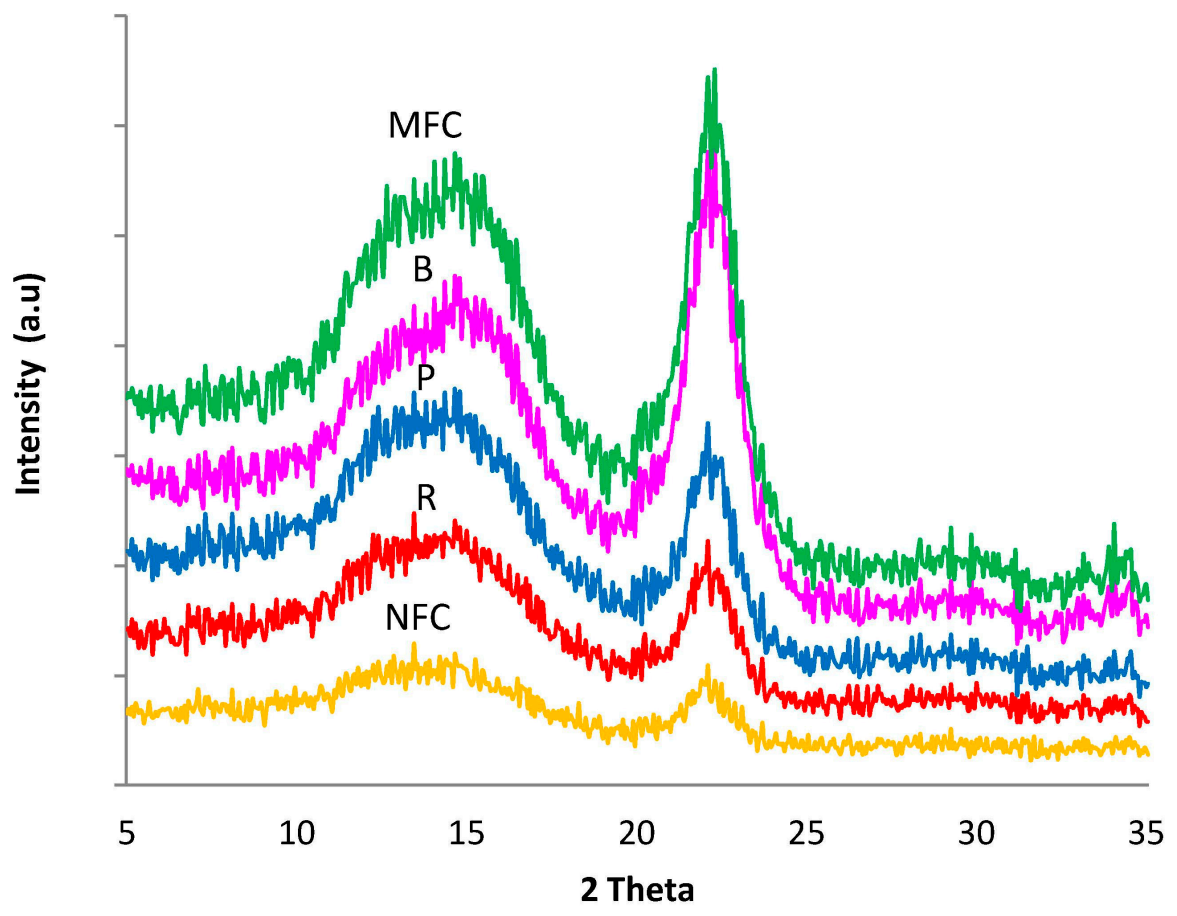

Figure 4 shows that the peaks at $15^{\circ}$ and $22.7^{\circ}$ are more defined for bleached fibers and further intensified in the case of MFC. This is attributed to the dissolution of cementing materials, such as lignin and hemicellulose, by chemical treatments, thereby increasing the crystallinity of MFC (80.42\%), as shown in Figure 5. Higher crystallinity of bleached EFB fibers (67.12\%) were obtained in this study as compared to the bleached EFB fibers reported by Jonoobi et al. [8]. Wherein, a percentage crystallinity of about $61 \%$ was gained for the soda pulping process of raw OPEFB fiber, which exhibits an effective purification process by removing lignin, hemicellulose, and others waxy materials. However, the percentage of crystallinity decreased from $80.42 \%$ to $42.52 \%$ with the HPH treatment of 
MFC. This was probably due to the breakdown of cellulosic hydrogen bond by the impact of pressure during nanofibrillation process of MFC using $\mathrm{HPH}$.

Figure 5. The percent crystallinity of the raw and treated cellulosic fibers.

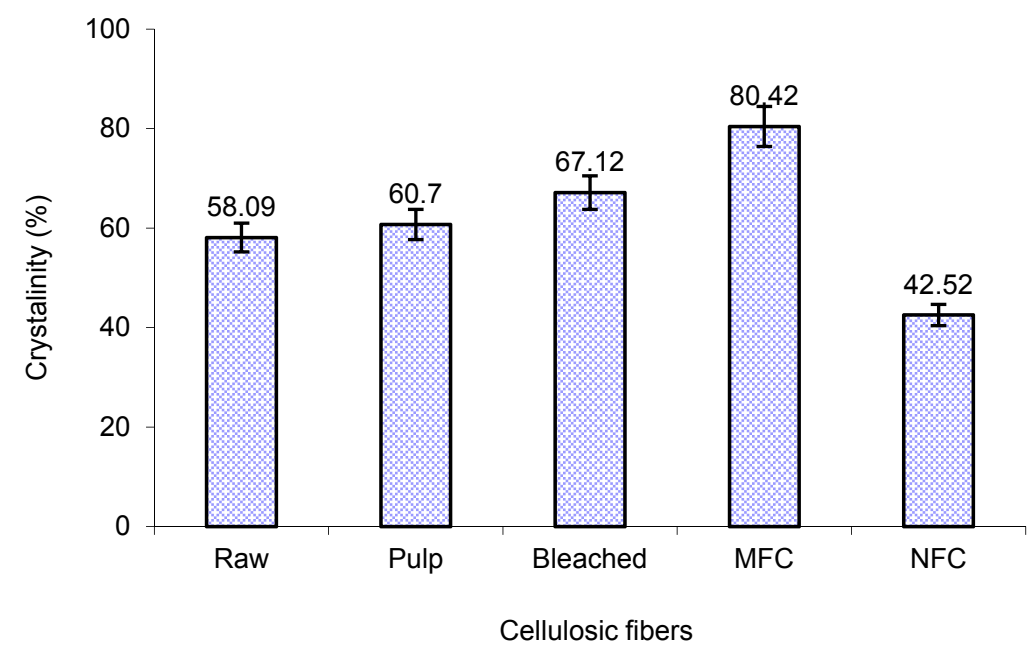

\subsection{Thermogravimetric Analysis (TGA)}

TGA was carried out to investigate the suitability of the samples for bio-composite processing. The thermal decomposition parameters were determined by the TGA curves, as shown in Figure 6 . The initial and final degradation temperature (IDT and FDT) and maximum degradation temperature $\left(T_{\max }\right)$, together with the percentage of char residue, were tabulated in Table 1. The initial weight loss started at $30{ }^{\circ} \mathrm{C}$ for all samples, and was attributed to the evaporation of the moisture in the fibers. After $370{ }^{\circ} \mathrm{C}$, the entire organic compound presented in the fibers degraded, black carbonaceous residue (inorganic compound), known as char, remained. The TGA curve of the raw EFB fiber showed four degradation steps related to (a) moisture evaporation, (b) hemicellulose, (c) cellulose, and (d) lignin degradation.

The TGA analysis of the raw EFB fiber showed that the peaks at 264 and $389{ }^{\circ} \mathrm{C}$ were caused by hemicellulose/lignin and $\alpha$-cellulose degradation, respectively. The degradation of the pulp fiber occurred from 308 to $389{ }^{\circ} \mathrm{C}$ while that of bleached fiber was in the range of $308-379{ }^{\circ} \mathrm{C}$ and is attributed to the degradation of cellulose. The MFC also showed the same trend of degradation, as shown by the raw fibers, with the degradation occurring from 253 to $389{ }^{\circ} \mathrm{C}$ except for an ash content of $14 \%$, which is lower in MFC when compared to the raw fibers. In the case of NFC, the degradation occurs from 300 to $379{ }^{\circ} \mathrm{C}$, while the percentage of ash content is lowest among the fibers studied (5\%), attributed to the almost complete removal of hemicellulose and lignin from the cellulose fibers.

As shown in Table 1, the $T_{\max }$, increasing from raw to NFC fibers, indicated that the treated fibers were more thermally stable and this is congruent with the crystallinity of the fibers. Although the crystallinity of MFC is higher compare to the other fibers, the maximum degradation temperature was found to be lower $\left(326^{\circ} \mathrm{C}\right)$. This might be due to the introduction of sulphate groups into the MFC surface during hydrolysis [28]. The highest maximum degradation temperature was found for NFC, $357{ }^{\circ} \mathrm{C}$, which is higher than the determined maximum degradation temperature $\left(339^{\circ} \mathrm{C}\right)$ of OPEFBs 
nanofiber by Jonoobi et al. [8]. The highest thermal stability was gained in NFC OPEFBs fiber because of the rapid defibrillation of MCC by the impact of high pressure HPH.

Figure 6. Thermogravimetric analysis graph of all oil palm fibers studied; raw (R), pulp (P), bleached pulp (B), MFC and NFC.

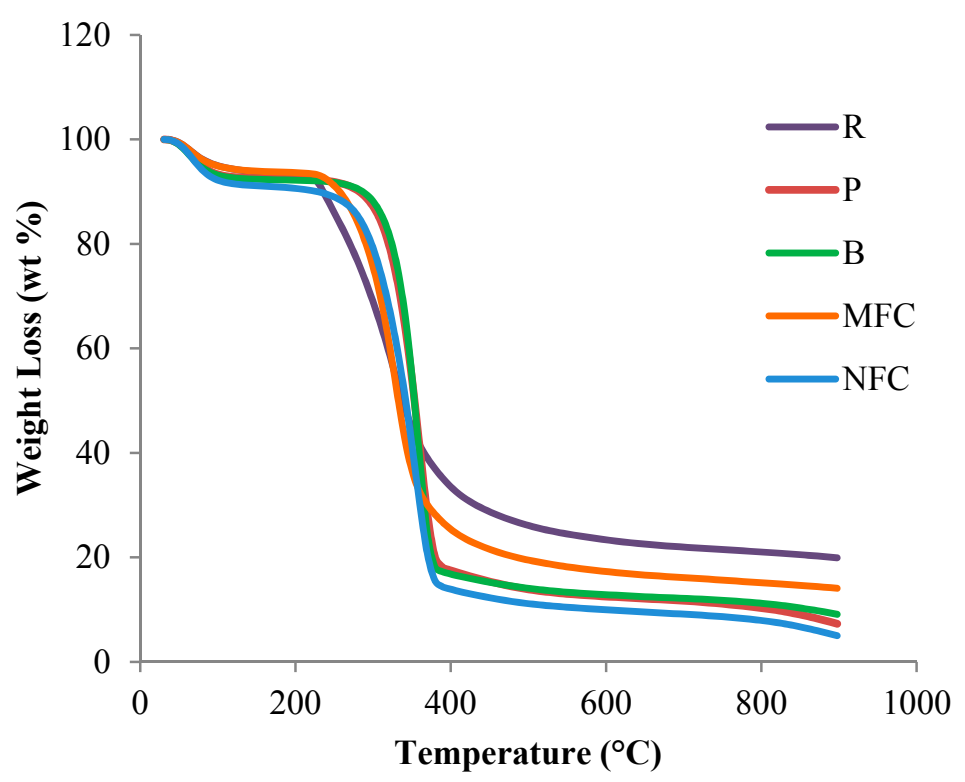

Table 1. Thermal parameters for the thermograms of all oil palm fibers studied.

\begin{tabular}{ccccc}
\hline EFB fibre & IDT $\left({ }^{\circ} \mathbf{C}\right)$ & FDT $\left({ }^{\circ} \mathbf{C}\right)$ & $\boldsymbol{T}_{\max }\left({ }^{\circ} \mathbf{C}\right)$ & Residue $(\%)$ \\
\hline Raw & $264 \pm 2.14$ & $389 \pm 2.42$ & $330 \pm 2.34$ & $19.90 \pm 0.50$ \\
Pulp & $308 \pm 2.32$ & $389 \pm 2.36$ & $349 \pm 2.26$ & $7.28 \pm 0.21$ \\
Bleached pulp & $308 \pm 2.41$ & $379 \pm 2.18$ & $354 \pm 2.49$ & $9.10 \pm 0.16$ \\
MFC & $253 \pm 2.73$ & $389 \pm 2.54$ & $326 \pm 2.12$ & $14.08 \pm 0.30$ \\
NFC & $300 \pm 2.43$ & $379 \pm 2.61$ & $357 \pm 2.48$ & $5.01 \pm 0.04$ \\
\hline
\end{tabular}

\section{Conclusions}

In this study, nanofibrillated cellulose fibers were successfully isolated from oil palm empty fruit bunch using combinations of sulphuric acid hydrolysis and high-pressure homogenization processes. Results showed that acid concentration and acid-to-fiber ratio play effective role in the fibrillate formation of cellulosic fibers. Analyses of the SEM images revealed that acid hydrolysis treatment did not affect the morphological structure of the treated fibers, but it is exhibited in a smaller particle dimension. Transmission electron micrographs analysis revealed that the nanofibrillation of the OPEFB cellulose fiber diameters were within the range of 5 to $10 \mathrm{~nm}$. FT-IR analysis indicated that the acid hydrolysis did not influence the chemical structure of the treated fiber and effectively remove lignin and hemicellulose from the raw cellulosic fiber. XRD analysis showed that the percentage of crystallinity of nanofibrillated cellulose was notably influenced by pressure of HPH. However, the TGA analyses exposed that the isolated NFC had a trustworthy maximal thermal durability. Based on the results, it was evident that the isolation of NFC fibers, using combinations of sulphuric acid 
hydrolysis and high-pressure homogenization processes, has the potential to be quality reinforcing agents for composite materials, due to prospective thermal stability along with minimal particle size formation. Thus, the combination of sulphuric acid hydrolysis and high-pressure homogenization processes could be utilized as an effective chemo-mechanical process for nanocellulose production from various cellulosic sources.

\section{Acknowledgments}

Authors would like to thank Universiti Sains Malaysia (USM) for providing the research grant (RUI:1001/PTEKIND/811195; 1001/PTEKIND/846107) and Malaysia Palm Oil Board (MPOB) for research fellowship.

\section{Author Contributions}

H.P.S. Abdul Khalil is the corresponding author of this work and supervisor of Ireana Yusra A. Fatah, Yalda Davoudpour and Rudi Dungani. Astimar A. Aziz is the co-advisor of Ireana Yusra A. Fatah and carried out part 1. Ireana Yusra A. Fatah worked on the isolated nanofibrillated cellulose using sulphuric acid hydrolysis and high-pressure homogenization as a chemo-mechanical process. Ireana Yusra A. Fatah, Yalda Davoudpour and Rudi Dungani conducted the morphological study and wrote the first draft of this work. Md. Sohrab Hossain conducted data analysis and critically reviewed the manuscript with the assist of H.P.S. Abdul Khalil and Amir Bhat. All authors read and approved the final manuscript.

\section{Conflicts of Interest}

The authors declare no conflict of interest.

\section{References}

1. Abdul Khalil, H.P.S.; Bhat, A.H.; Ireana Yusra, A.F. Green composites from sustainable cellulose nanofibrils: A review. Carbohyd. Polym. 2012, 87, 963-979.

2. Jawaid, M.; Othman, A.N.; Saba, Y.A.S.; Paridah, M.T.; Khalil, H.P.S.A. Effect of chemical modifications of fibres on tensile properties of epoxy hybrid composites. Int. J. Polym. Anal. Charact. 2014, 19, 62-69.

3. Fahma, F.; Iwamoto, S.; Hori, N.; Iwata, T.; Takemura, A. Isolation, preparation, and characterization of nanofibers from oil palm empty-fruit-bunch (opefb). Cellulose 2010, 17, 977-985.

4. Fahma, F.; Iwamoto, S.; Hori, N.; Iwata, T.; Takemura, A. Effect of pre-acid-hydrolysis treatment on morphology and properties of cellulose nanowhiskers from coconut husk. Cellulose 2011, 18, 443-450.

5. Nazir, M.S.; Wahjoedi, B.A.; Yussof, A.W.; Abdullah, M.A. Eco-friendly extraction and characterization of cellulose from oil palm empty fruit bunches. Bioresources 2013, 8, 2161-2172.

6. Abdul Khalil, H.P.S.; Davoudpour, Y.; Islam, M.N.; Mustapha, A.; Sudesh, K.; Dungani, R.; Jawaid, M. Production and modification of nanofibrillated cellulose using various mechanical processes: A review. Carbohyd. Polym. 2014, 99, 649-665. 
7. Siddiqui, N.; Mills, R.H.; Gardner, D.J.; Bousfield, D. Production and characterization of cellulose nanofibers from wood pulp. J. Adhes. Sci. Technol. 2011, 25, 709-721.

8. Jonoobi, M.; Khazaeian, A.; Tahir, P.M.; Azry, S.S.; Oksman, K. Characteristics of cellulose nanofibers isolated from rubberwood and empty fruit bunches of oil palm using chemo-mechanical process. Cellulose 2011, 18, 1085-1095.

9. Chan, H.C.; Chia, C.H.; Zakaria, S.; Ahmad, I.; Dufresne, A. Production and characterisation of cellulose and nano-crystalline cellulose from kenaf core wood. BioResources 2012, 8, 785-794.

10. Yu, M.; Yang, R.; Huang, L.; Cao, X.; Yang, F.; Liu, D. Preparation and characterization of bamboo nanocrystalline cellulose. BioResources 2012, 7, 1802-1812.

11. Qua, E.H.; Hornsby, P.R.; Sharma, H.S.S.; Lyons, G. Preparation and characterisation of cellulose nanofibres. J. Mater. Sci. 2011, 46, 6029-6045.

12. Abdul Khalil, H.P.S.; Mahayuni, R.; Bhat, I.U.H.; Rudi, D.; Almulali, M.Z.; Abdullah, C.K. Characterization of various organic waste nanofillers obtained from oil palm ash. BioResources 2012, 7, 5771-5780.

13. Lu, P.; Hsieh, Y.L. Preparation and characterization of cellulose nanocrystals from rice straw. Carbohyd. Polym. 2012, 87, 564-573.

14. Jonoobi, M.; Harun, J.; Tahir, P.M.; Shakeri, A.; SaifulAzry, S.; Makinejad, M.D. Physicochemical characterization of pulp and nanofibers from kenaf stem. Mater. Lett. 2011, 65, 1098-1100.

15. Turunawarasua, D.; Chana, Y.P.; Muhaiminb, W.P.A.W.; Honb, L.H.; Syedb, O.B.; Nguyenb, T.H.V.; Borhanb, A.B. Thermo-economic analysis of a novel conceptual process model for sustainable power plants using empty fruit bunches. Int. J. Chem. Environ. Eng. 2013, 4, 310-315.

16. Brinchi, L.; Cotana, F.; Fortunati, E.; Kenny, J.M. Production of nanocrystalline cellulose from lignocellulosic biomass: Technology and applications. Carbohyd. Polym. 2013, 94, 154-169.

17. Klemm, D.; Kramer, F.; Moritz, S.; Lindstrom, T.; Ankerfors, M.; Gray, D.; Dorris, A. Nanocelluloses: A new family of nature-based materials. Angew Chem. Int. Ed. 2011, 50, $5438-5466$.

18. Lasseuguette, E.; Roux, D.; Nishiyama, Y. Rheological properties of microfibrillar suspension of tempo-oxidized pulp. Cellulose 2008, 15, 425-433.

19. Siró, I.; Plackett, D.; Hedenqvist, M.; Ankerfors, M.; Lindström, T. Highly transparent films from carboxymethylated microfibrillated cellulose: The effect of multiple homogenization steps on key properties. J. Appl. Polym. Sci. 2011, 119, 2652-2660.

20. Jonoobi, M.; Harun, J.; Shakeri, A.; Misra, M.; Oksman, K. Chemical composition, crystallinity, and thermal degradation of bleached and unbleached kenaf bast (Hibiscus cannabinus) pulp and nanofibers. BioResources 2009, 4, 626-639.

21. Iwamoto, S.; Nakagaito, A.N.; Yano, H. Nano-fibrillation of pulp fibers for the processing of transparent nanocomposites. Appl. Phys. A Mater. 2007, 89, 461-466.

22. Pan, M.; Zhou, X.; Chen, M. Cellulose nanowhiskers isolation and properties from acid hydrolysis combined with high pressure homogenization. BioResources 2013, 8, 933-943.

23. Wan Rosli, W.D.; Leh, C.P.; Zainuddin, Z.; Tanaka, R. Optimization of soda pulping variable for preparation of dissolving pulps from oil palm fiber. Holzforschung 2003, 57, 106-114. 
24. Segal, L.; Creely, J.J.; Martin, A.E., Jr.; Conrad, C.M. An empirical method for estimating the degree of crystallinity of native cellulose using the X-ray diffractometer. Text. Res. J. 1959, 29, 786-794.

25. Abdul Khalil, H.P.S.; Yusra, A.F.I.; Bhat, A.H.; Jawaid, M. Cell wall ultrastructure, anatomy, lignin distribution, and chemical composition of Malaysian cultivated kenaf fiber. Ind. Crop. Prod. 2010, 31, 113-121.

26. Haafiz, M.K.M.; Eichhorn, S.J.; Hassan, A.; Jawaid, M. Isolation and characterization of microcrystalline cellulose from oil palm biomass residue. Carbohyd. Polym. 2013, 93, 628-634.

27. Ciolacu, D.; Ciolacu, F.; Popa, V. Amorphous cellulose-structure and characterization. Cell. Chem. Technol. 2011, 45, 13-21.

28. Jahan, M.S.; Saeed, A.; He, Z.B.; Ni, Y.H. Jute as raw material for the preparation of microcrystalline cellulose. Cellulose 2011, 18, 451-459.

(C) 2014 by the authors; licensee MDPI, Basel, Switzerland. This article is an open access article distributed under the terms and conditions of the Creative Commons Attribution license (http://creativecommons.org/licenses/by/4.0/). 